\title{
THE DISAPPEARANCE OF THE TROPICAL FORESTS OF AFRICA
}

\author{
André Marie A. Aubréville
}

\author{
Conservator of Waters and Forests, Paris, France
}

A glance at a map showing the distribution of vegetation in Africa focuses attention on a large patch of green centered in the equatorial zone. This green area represents a vast expanse of dense forest 4800 kilometers wide, stretching from Sierra Leone to the great East African lakes, and covering parts of Liberia, the Ivory Coast, the Gold Coast, Nigeria, the Cameroons, French Equatorial Africa, and the Belgian Congo ${ }^{1}$.

This enormous forest area would appear to present an almost unlimited reserve of timber to be drawn upon at will, if not today, at least in the future, whenever the world's timber re-

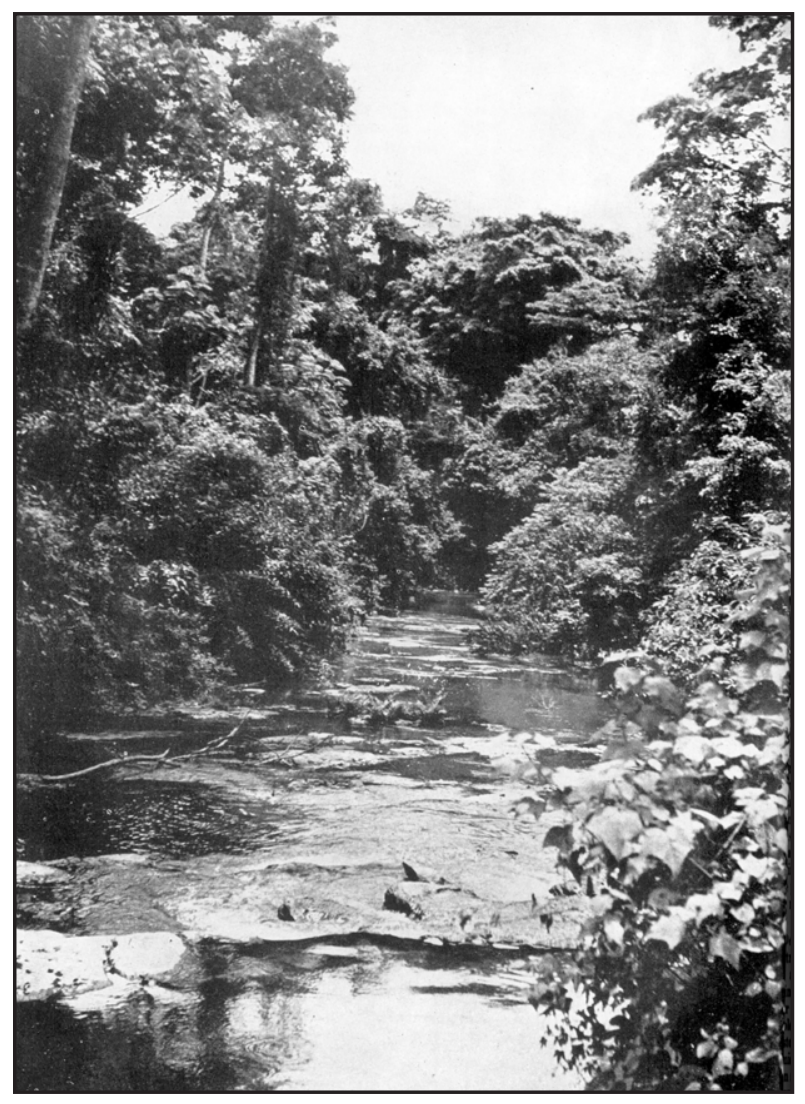

Figure 1. Riches of the tropical forest. quirements become so great that the temperate zone can no longer satisfy them.

\section{THE EQUATORIAL FOREST}

The equatorial forests of Africa have been little exploited and they contain phenomenal quantities of timber. They cover areas having a particularly favorable climate: there is abundant rainfall spread evenly over the year, except for an occasional short period of drought lasting three months at the most; the temperature remains at an average of $25^{\circ}$ to $26^{\circ}$ centigrade; humidity is very high and there is seldom a lack of moisture in the air. Such conditions are scarcely enjoyable for man but certainly afford a most suitable environment for forest growth and industrial crops like palm, and they produce here the highest yields of oil, rubber, cacao, coffee, and bananas.

\section{Decline of the Equatorial Forest Belt}

Outside this central zone, Africa is devoid of great forest areas. On a large-scale map, the few forests of French Guinea, Uganda, Kenya, Tanganyika, and Angola appear as insignificant dots, and, therefore, over the whole area of tropical Africa the average density of stocking is low despite the size of the forests of the humid zone.

In studying Africa's climate, one is surprised to discover that, over a fringe from a few dozen to two or three hundred kilometers in breadth around the equatorial forest zone, the climate is the same as that prevailing in the forest. All the climatic conditions favoring a dense, humid forest are there, and yet one finds vast prairies of tall grasses, sometimes dotted with shrubs or small, scattered trees, some-

\footnotetext{
${ }^{1}$ Place names are those current at the time of original publication in 1947.
} 
times bare of any such vegetation. They alternate with areas supporting food crops or are interspersed with patches of high forest. Considering that plant types are conditioned by environment and more particularly by climate, these forest borderlands constitute an astonishing anomaly.

In view of these dense forest stands adjacent to savannah land, the natural assumption would be that the forest "climax" type, favored by climate, was slowly encroaching on the grassland, and that we were witnessing an ecological transition. This explanation is, however, inaccurate. The African continent is an old insular shelf that came into existence in primeval times. The forest has had ample time to occupy all areas having favorable environmental conditions. One has only to realize the speed with which it is capable, even today, of invading recent alluvial deposits to agree that this is so.

A study of the woody flora of the borderland savannahs points conclusively to forest regression. The small trees and shrubs that have established themselves on the savannahs belong to a few species only. They are members of a common light-demanding plant community to be found in open spaces throughout tropical Africa. Here they are alien species that have emigrated from regions having a drier climate. Their hardiness, the ease with which they propagate, their resistance to destructive factors, and their ability to throw out new shoots and suckers give them that power of extending their range, which is common to all weeds. They do not belong to the denseforest flora and in any case could not survive under the closed canopy.

\section{Reasons for the Forest Regression}

How did the regression from high forest come about? The process continues to unfold before our eyes.

The primary cause can be ascribed to the clearing done by native populations who, living in a compact, unbroken forest, are forced to cut down trees in order to allow the sun to reach their crops. These clearings are not peculiar to Africa. In all tropical countries, natives use the same methods of preparing land for cultivation. They fell trees and burn them and set fire to those left standing. After one or two crops, they abandon the exhausted soil. A low, dense growth of shrubs, small trees, and creepers, termed secondary scrub, rapidly invades the cleared space. It consists of species different from those of the original forest. The natives meanwhile start clearing further tracts of forest where the humus and soil, enriched by wood ash from burnt vegetation, will provide adequate crops.

The primitive nomadic method of agriculture has been practiced by all native populations since time immemorial, and the original forests have, for the most part, been replaced by secondary forests. The latter, provided conditions are favorable, may slowly revert to the original type but such is not always the case. Recovery is poor when the soil has become extremely impoverished, where slopes are worn away by erosion, or where local climatic conditions include a dry season particularly long and arid. In such cases, the soil covering, instead of secondary forest, often becomes savannah-type grassland or brushlands.

The virgin forest is not prone to fire, but the stunted secondary scrub, the savannah, and the brushland become sufficiently desiccated during the dry season to be inflammable. Fires raging every year over the savannah manage to penetrate each time a little farther into the high forest by attacking the grass-type plants and secondary scrub that do not resist the flames.

Forest regression is very noticeable where, as frequently happens, the local native population concentrates on clearing land on the forest edge, thus opening up gaps through which the fires can penetrate; or in hilly areas where crops are planted on rather steep banks covered only with a thin layer of soil.

It is for these reasons that the forest borderland zone now exhibits such varied characteristics: scattered remnants of the primeval 
forest, not yet attacked or protected against fire by accidents of topography, such as rocky ridges or very humid valleys; thickets of low scrub, remains of the former secondary scrub that followed land clearings; areas covered with tall grasses and savannahs, bare except for a few tall half-burned trees, bearing witness to recent clearing; and older savannah land already supporting shrubs and small trees belonging to an alien xerophilous flora.

\section{Characteristics of the Older Regression and Present Conditions}

At present, two factors with conflicting tendencies are affecting the rate of disappearance of the dense African forest.

Native populations, in general, tend to move from savannah lands to the forest, first settling around the outskirts, then pushing back the forest limits. Gradually they reach portions of the forest that are increasingly humid and have a greater power of recovery and resistance to fire. The spread of savannahs tends in this way to slow down, as compared to the past when settlers were dealing with less resistant forests under drier climates; the farther the advance towards the heart of the equatorial forest, the more the transformation into savannah is held in check. On the other hand, intensive land clearing has become more general with the present-day development of agriculture, particularly of industrial crops, and certain populations have increased in density while economic development in general has given rise to constant shifts in populations, thus increasing the burden on forests.

The contraction of the high evergreen forest may appear slow. There are those who deny that anything of the sort is taking place because they notice no appreciable change from one year to the next, except for occasional nibbles at the forest outskirts by brush fires that, on dry soils, may sometimes succeed in penetrating the understory for some yards. In fact, the surrender of the forest to the savannah is spread over vast areas around the perimeter.
There is, as it were, slow deterioration altering the landscape in a manner impossible to detect over short periods. Somehow the forest dissolves almost imperceptibly into savannah.

In the past, this was not always the case in drier areas likely to be cleared for cultivation. Ground fires were likely to spread directly to the understory and even to the forest canopy. Forest decay was then definite and rapid. It is because all the forests that could easily be set on fire were burned out long before Europeans ever arrived that, today, in regions having a climate more properly belonging to a forest climax, we see in contrast either savannah land, bare or supporting an alien flora, or the high evergreen forest, well able to protect itself against man's incursions and the fires that lick at its fringes. The equatorial forest is still diminishing today but at a much slower pace than before.

Were it not for the annual ground fires, the forest would of itself regain much of the ground that it has lost. Every experiment so far demonstrates that recovery is rapid when the soil has retained its humus content and a good structure. Certain observers have reported cases of the forest extending its range, but what this presumably means is rather that the forest has re-established itself where particular circumstances have arrested the ravages of the annual fires.

Clearing the high evergreen forest eventually produces important modifications in the composition of the forest growing stock. The species of the virgin forest tend to be replaced by rapidly growing light-demanding species. In certain fortunate cases, the latter are economically more desirable than the former, as for instance with gaboon (okoumé), Aucoumea klaineana Pierre in Gabon, and Juniperus procera Hochst in burned areas of high altitude forest in East Africa.

\section{Dry Forests and Wooded Savannahs}

The equatorial forests form an impressive mass in the heart of Africa but represent only a 
small percentage of the total land area of the continent, even when we exclude the Sahara, the maritime deserts of the Somali Coast, and the west coast of southern Africa.

Tropical Africa, which has two well-defined seasons, the rainy season and a long dry season, is covered with vast stretches of wooded savannah, and with open forests of smallsized trees, which at times grow close enough together to resemble forests of the temperate zones; forests in which, however, there would be a soil covering of grasses.

Each year at the beginning of the dry season, this country is swept by fires. These, however, are only ground fires. Trees and shrubs may have their foliage singed but as a rule escape burning. In the wake of the fires, the earth lies covered with a black dust of carbon and ashes and the tree stems appear scorched. Nature seems dead, but should rain fall or dew form a few times, a soft haze of grass covers the soil and the trees turn green again. Nature comes alive, fairer even than before the coming of the flames, when only dried and withered leaves were to be seen.

Each year the same phenomenon is repeated. It seems as if things had always been so, but that is not true. Actually, we are witnessing the death struggle of a plant world, slow stages in the drying up and degeneration of tropical Africa.

The insidious thing about it is that, generally speaking, nobody seems to realize it, in much the same way that the friends of a very sick man, who has been an invalid for years, get so used to seeing him in an ailing condition that they forget that once he was in perfect health. They cease to perceive the slow encroachment of disease until one day the sick man dies.

In Africa, it is now taken for granted that fires, savannahs, and sparse forest stands constitute a state of equilibrium that has always existed. Certain geographic ecologists, who do not yet fully comprehend the biological evolution of these associations, call these wooded savannahs a "climatical" type of vegetation.
Yet a look at these trees and shrubs suffices to show the damaged, stunted boles and the scraggy tops unable to develop normally because the branches are scorched each year, and to prove that the young shoots and seedlings are annually consumed by fire except for a few that manage with difficulty to survive. It is only because the plants have such remarkable vitality and such power to throw out shoots and suckers and to develop a thick and often corky bark that this woody vegetation survives at all.

The naturalist, however, can but wonder at this unnatural association of grasses and trees - the grasses tend to smother seedlings and young plants and the shade of the trees tends to kill the light-seeking grasses. If it were not that the annual fires kept the forest cover open and allowed the grass to regenerate, the latter would disappear in a matter of years or centuries, depending on the particular environment.

The typical African landscape of wooded savannahs is artificial, except in the desert borderland areas. It has come into existence from the effects of fire and clearings on the old, dense, close-canopied high forest, with shrubby understory but with no grass undergrowtha forest of a type altogether different from the humid equatorial forest, the formation of which has been lost in the mists of time.

All the forests, which in the past covered the arid regions of Africa with a huge unbroken mantle, have today ceased to exist, save for a few traces that have to be painstakingly tracked down in uninhabited areas; there, however, it is a surprise to find in closed communities all those species of trees and shrubs that are customarily found in isolated stunted groups on the wooded savannahs. This is their real habitat. Here species are associated together according to climate and soil, whereas ordinarily they seem to be thrown together haphazardly with no apparent reason. There is a compact understory of shrubs, woody climbers and creepers below a forest canopy, varying in height from 12 to 20 meters, sometimes 


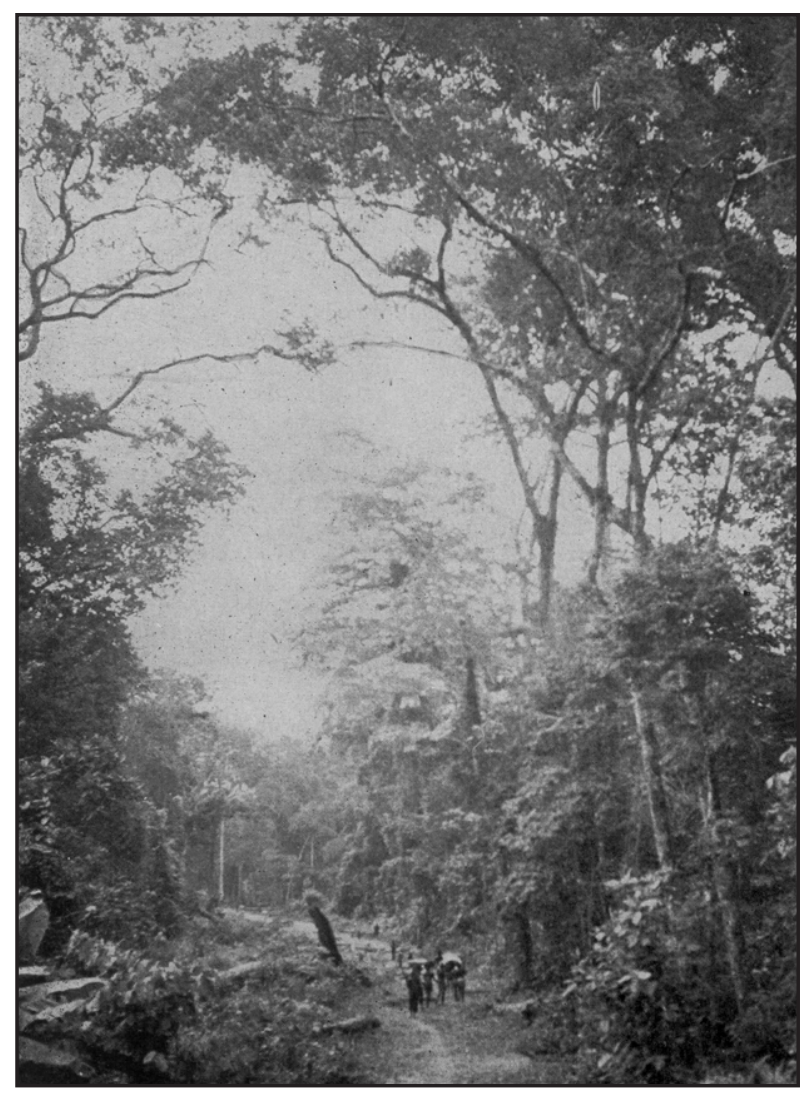

Figure 2. Remnants of the dry forest.

closed, sometimes partly open, depending on the soil. Various tree associations are to be found with some particular dominant species, for instance, with Anogeissus; with Isoberlinia-Uapaca-Monites; with tan leguminous Burkea-Erythrophleum tetrapleura-Prosopis; with Parkia-Pterocarpus; with BrachystegiaIsoberlina; with Cryptosephalum; with Detarium-Parinari-Afzelia; with Combretum-Terminalia; and with Anogeissus-Boswellia. Such associations are still to be found forming sizable forests in southern Africa (northern Rhodesia, Katanga, Angola), and to a lesser extent in Ubangi-Shari, in French Guinea, and in Casamance.

These latter stands will sooner or later disappear. The process can be watched, as the clearing of land for cultivation proceeds. Sometimes fire alone is sufficient to destroy the forest. The undergrowth is most vulnerable to fire during the dry season. Fires gener- ally sweep along lanes into the forest according to the direction of the wind and the degree of dryness of the jungle. The more resistant patches are left isolated. Grass species immediately establish themselves in the clearings and in the following season feed anew the flames and help the fires to spread farther. The dominant trees are more or less able to resist because of the protection afforded by their thick bark and their deep root system. Nevertheless, they often suffer damage at the base and the cumulative effect of several seasons' fires accounts for the death of a great many of them.

Thus the forest is gradually thinned and reverts to grassland. In the course of centuries, savannahs tend to replace the forest and the latter would have long since vanished had it not been for the exceptional vitality of some of its component species that manage to survive in spite of all adverse circumstances. But as long as fires remain an annual occurrence, the forest will continue to deteriorate.

The native tribes set fire to the land for numerous, more or less justifiable reasons. The tall, dry grasses are an obstacle to the native African. They impede his movements. They hinder him in hunting and in growing crops, and the simplest way to get rid of them is to set them afire. In reality, of course, the more the land is cleared, the more easily the grasses spread, but the bushman does not look ahead. He only tries to solve his immediate difficulties. The grasses smother him, so he simply sets fire to them.

In the same way, primitive man set fire to the dry high forest. Tangled thickets, creepers, and thorns were not easy to penetrate. The first fires were kindled so that man could move about more freely. As populations increased, and as wars broke out between tribes over the possession of hunting or fishing grounds, the migrations of both conquerors and vanquished multiplied fire hazards. Later, agriculture and stockbreeding developed and farmers and shepherds, in their turn, cleared land and set 
fire to the forest. These developments, which changed the face of Africa, date back to a time so far distant that no memory of them is left. The change was complete and general. Were it not for the forest areas that have survived, it would be difficult to imagine how things had once been.

\section{CONSEQUENCES OF THE DISAPPEARING FOREST}

\section{Effect on Timber Production}

In general, it can be said that tropical Africa is tending to become savannah. Economically, for both local and world forestry, this tendency must have serious consequences.

Except for the equatorial forest regions, Africa already imports timber. Further progress and increase of its population will only make this situation worse. Where the climate is dry, haphazard clearing around centers of population has already resulted in a total disappearance of woody growth. Now the women of a community are often obliged to walk for hours in order to gather firewood, which they will have to carry back to the village; otherwise, they must buy their firewood for cooking at a high price in the market place. Timber has become scarce; straight-stemmed trees are to be found only along far distant riverbanks. The problem of wood shortage has to be faced everywhere in these dry, populated areas, and the problem is indeed trying for both the local population and the administration.

The resources of the great equatorial forests, on the other hand, greatly exceed the needs of the local population. They are being used for a far from negligible export trade, which could grow in importance in the Ivory Coast, the Gold Coast, Nigeria, Cameroons, Gabon, the central Congo region, and the Belgian Congo. Timber reserves are still very considerable, compared with the relatively insignificant quantities now taken out for export.
The outlook for the future, however, is disturbing since each year, as further land is cleared, part of these reserves go up in smoke. Secondary growth of medium and small trees covers larger and larger areas as time goes on. The timber is soft, nondurable, and good for no particular use. On the average, one- to twothirds of the forest area consists of secondary growth of no great value. When the shortage of timber forces the world to start giving serious consideration to African woods, the vaunted equatorial forests might only be able to supply an insignificant contribution to world production, unless precautions are taken now.

In certain areas, however, climate and species offer wonderful possibilities for rapid growth of timber. It would be possible by very simple silvicultural methods and with no great financial outlay to establish rich forests on the coastal areas of the Gulf of Guinea, from the Ivory Coast to Gabon.

\section{Effect on Living Conditions in Africa}

The effect of the disappearance of the forest on living conditions in Africa is far more serious than its effect on timber production, since the future of mankind on a whole continent is at stake. The removal of the forest cover influences the climate, soil conservation, and water reserves far more than would be the case anywhere else in the world.

To begin with, as was mentioned earlier, we are dealing here with a general phenomenon that affects the greater part of tropical Africa and thus assumes the proportions of a major factor in regulating climatic conditions. For the duration of the dry season, lasting from four to nine months (except in the desert and desert borderland countries), the bare, scorched earth is exposed to the sun's intense heat and is subject to a high rate of evaporation, caused either by the direct heating of the soil or by the dryness of the atmosphere and the desiccating winds that prevail during this season. The major result of this dry heat is a change in the 
physical structure of the soil, making it less resistant to the forces of erosion that are set in motion by the violent rains ending the dry season. There is also a drop in the water table that, though made up to some extent by later rains, still affects the total water supply for the year.

The exposure of the soil to excessive heat, followed by severe leaching, leads to erosion in all its forms: gully erosion and sheet erosion, loss of productivity through the burying of humus, and the disintegration of the colloidal structure of the soil-all important elements in soil fertility. The African soil deteriorates with a rapidity unknown in temperate zones where exposure to the sun is less intense and of shorter duration. Deterioration is also accelerated by the loss of carbon and nitrogen as a result of the burning of the vegetation during the period of ground fires.

For the reasons enumerated above, the crops of the native farmers yield very little. There are, generally speaking, no fertilizers to replenish the soil, and as a result, Africa is a poor country agriculturally. The natives hardly question this state of affairs, having long since become accustomed to meager crops. When the soil is exhausted in one place, they can move and clear further areas of forest. Wooded land is still to be found where, although the trees have deteriorated, the soil is still capable of cultivation. Thus the process will continue so long as virgin soil remains to be cultivated, but it cannot go on forever.

One odd result of erosion, following deforestation, can be seen in certain regions of undulating plateaus. Beneath the topsoil are found hard ferruginous and lateritic strata, probably of fossil origin. When the surface soil wears away, these strata are exposed and harden into a ferruginous or lateritic shell that will support no vegetation other than barren grass. Such regions (French Guinea, UbangiShari) acquire a semi-desert character in spite of abundant rain.

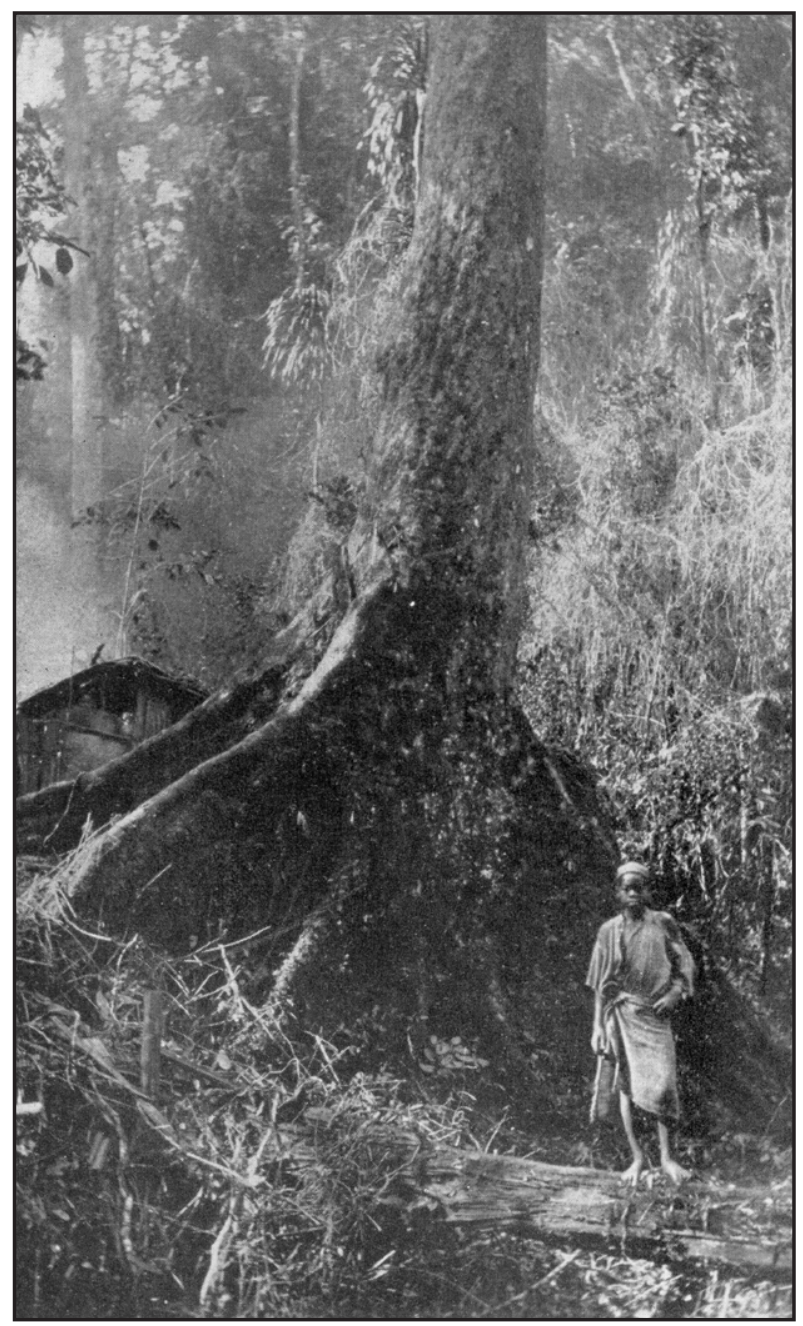

Figure 3. Remains of the forests of Madagascar.

\section{Effect on Precipitation}

Africa is a continent badly situated with regard to the major atmospheric currents. On the Atlantic coast, the marine trade winds veer off in other directions; in the north Atlantic, they are diverted and blow from northeast to southwest; in the south Atlantic, they blow towards South America, from southeast to northwest. The trade winds are diverted by the low pressures over the continent and only cool the coastal regions; they bring no rain but merely humidity and fog.

During the Northern Hemisphere winter, northern Africa is swept by dry winds coming from the Sahara. These are continental trade 
winds, called "harmattan" in West Africa and the "Egyptian current" in the Nile region. They exercise a drying effect up to the Gulf of Guinea in West Africa, and to the Equator and even beyond in Central Africa. Northeast Africa receives the Asiatic winter monsoon. This wind is usually dry but, after passing over the Indian Ocean, it brings a few light winter rains into Eritrea and Somaliland.

During this same time of the year, southern Africa, where it is the warm and rainy season, is under the influence of the Indian Ocean trade winds, which blow in a general southeast to northwest direction. They cause rain to fall on the coastal areas, but they dry up rapidly and bring little rain inland. During the southern winter (northern summer), they are drawn to the overheated Asiatic continent and, by avoiding Africa, are drawn into the powerful air currents of the Asiatic wet monsoon; East Africa, however, receives very little rain.

Thus, while it gets little benefit from the major air currents emanating from the sea, Africa is much exposed to dry, continental winds that absorb its moisture reserves, or to sea winds that have lost their water content. Fortunately, there is one important exception, without which Africa would have dried up long ago. The equatorial Atlantic monsoon, blowing from the southwest towards the continent, brings abundant summer rains. Drawn inland by low barometric pressure, it penetrates far into the heart of the continent up to the southern borders of the Sahara and crosses the continent to Abyssinia.

The amount of rain originating from the sea and brought in by the monsoon is important, but experiments carried out in Africa to determine the proportion in rainfall between water vapor from ground evaporation and from sea winds, have shown that over half, or even two-thirds, originated from ground evaporation. Evaporation from the ground is governed by the water reserves in the soil. Anything that tends to decrease the latter affects the former. Deforestation involves the loss of soils that constitute reservoirs for the accumulation of water. It exposes these soils to evaporation and to desiccation during the prolonged dry season so that it cannot but decrease Africa's water reserves and, in the long run, the amount of precipitation.

The dry forests, which once covered the major portion of tropical Africa, are not of much importance as far as timber production is concerned, except locally. Their role consists in protecting the soil against erosion and desiccation during the dry season. Their disappearance from whole areas probably has had, long before the present age, a continuously unfavorable influence on the climate and undoubtedly has had disastrous effects on the soil.

The diminishing surface of the equatorial forests has also had other results. A vast forest mass can affect the climate through the great amount of moisture it releases into the atmosphere from evaporation, which not only gives rise to local rainfall but also increases the amount of precipitation in the warmer deforested areas surrounding the forest. Early in the century, a study was made of the influence of forests on rainfall in Europe. Experiments were confined to one particular forest and the results were inconclusive. They could not have been otherwise. Only immense stretches of forest land, such as are found in equatorial areas, are capable of producing sufficient evaporation to exercise a climatic effect. Furthermore, the moisture thrown off by evaporation from a forest is often carried long distances by air currents before becoming condensed and precipitated as rain.

Masses of equatorial forests help to keep dry areas moist and to increase the amount of rainfall in such regions even when they are located quite a distance away. Their effect is comparable to that of the sea or of great lakes - the presence of the equatorial forest approximating climatically that of deep ocean gulfs reaching into Africa. The monsoon, blowing inland from the sea, rapidly sheds 
most of its moisture in the coastal belt and would soon be unable to produce abundant rains in the heart of Africa if it were not reinforced along its course by vapor from large rivers, marshlands, soil, and vegetation. The equatorial forests of the Guinea coast assume their greatest importance at the beginning and end of the dry seasons, when the soil left uncovered by the action of fire or covered with dry savannahs is desiccated on the surface and only the forests can still yield up moisture to the monsoon winds. Without them, the rainy season of the Sudanese regions would probably be of shorter duration.

The amount of rainfall over the southern borderland regions of the Sahara depends directly on the Atlantic monsoon. When the latter is active, rainfall is comparatively abundant. If not, a drought year results and famine strikes man and beast. Additional rainfall at the beginning and end of the dry season depends on the moisture supplied to the monsoon by the coastal forest regions of the Gulf of Guinea.

\section{Drying-up of the Climate of Inner Africa}

What has been said above regarding the effect of African forests upon environment makes it probable that the wholesale destruction of inland forests would accelerate deterioration of vegetation and soil in Africa and bring about acute desert conditions. These changes in the aspect of the vegetation and correspondingly in the environment took place for the most part, as previously pointed out, at remote epochs long before the advent of Europeans. They continue even today wherever there are any forests left. It is surprising to note the ease with which it was possible for man to set fire to such large areas within periods of time that are relatively short when compared to the age of the forests covering Africa.

Resistance to fire varies considerably according to the type of forest. Dense humid forests protect themselves better against all de- structive agencies. Certain types of dry, closed, or semi-closed forests are very prone to fire damage. They deteriorate and become open forests or wooded savannahs but they survive somehow and, should the threat of fire be removed, could again become high forests. Other forest communities, on the contrary, may disappear altogether with great rapidity. This is the case, for instance, with the forests of western Madagascar that are almost nonexistent today, with the forests of the lower Congo and the Mayomba in south Africa, with FutaJalon in French Guinea, and probably with a great many others. Everything tends to show that these forests, so easy to transform into savannahs, are not in biological equilibrium with the present climate, which has apparently become drier than the climate prevailing during the remote epochs when these forests came into being.

Such a theory is not improbable but it is impossible to prove it by meteorological statistics, since, with few exceptions, such data have only been collected in the last fifty years, a mere fleeting instant in the biological age of the earth. What we do know is that the climate of tropical Africa changed several times during the Quaternary Age and probably also during prior geological ages. Concurrently with the glacial periods of the temperate zones, Africa had alternate periods of drought and heavy rainfall that furthered the formation of deserts and of the equatorial forests.

Remnants of old canal systems in the Sahara, traces of human occupation, certain facts established historically, and vestiges of a tropical flora south of the Atlas Mountains - all point conclusively to the presence of humid periods. South of the Sahara, in Senegal, the Sudan, Nigeria, and in Tchad, the sandhills (ergs), now hemmed in by vegetation and the cloak of sand covering vast expanses, prove conversely that desert conditions formerly extended south far beyond the present limits. The forest vegetation of West Africa presents a curious mixture of different floras that developed as environ- 
ment changed with climatic phases. Some have remained to form groups of species that have more or less adapted themselves to new environmental conditions, though their presence seems ecologically abnormal.

On the basis of the evidence found, it is therefore possible that the destruction of forests over the major portion of tropical Africa is only a delayed consequence of the drying-up of the climate. Forests that had adapted themselves to favorable climatic conditions now no longer existing might nevertheless have survived until today, as indeed some have, thanks to the well-known fact that forests create a special environment of their own favorable to perpetual regeneration and that, in some way, isolates conditions within them from the general prevailing climate. But when the native tribes in Africa began to multiply, fire upset the delicate balance that had been established between the forest and the dry climate. This was the beginning of the disappearance of the forest; the soil became exposed to the all-powerful tropical sun and the desiccating winds.

\section{CONCLUSIONS}

Deforestation of Africa is going on now as it has been for ages past. At present we are witnessing the finishing touches to a process that probably started before the dawn of history and reached a climax during the unknown era when the first great invasions of man into Africa took place.

Man has set fire to the forest for the same reason that he has hunted, in order to be able to survive in the midst of a hostile nature. By destroying indiscriminately, however, he has only added to the difficulties a tropical climate imposes. Now that the curse that has been plaguing Africa has been identified, it is imperative that measures be taken to counteract the evil.

The African native is heir to all sorts of woes - famine, epidemics, malnutrition, etc. All countries with an interest in the life of Af- rica are striving to remedy these many misfortunes of the native populations, but it is impossible to better their lot permanently in an environment that is contrary to their way of life. The social progress of the native population is linked with the development of their agriculture, of the means of production, and of adequate living conditions in their countries. The wholesale disappearance of the forests tends, as we have shown, to make Africa a continent less and less favorable to man's progress, save in a few favored sections.

Is it possible to take adequate measures to protect Africa, its soil, and its forest cover? The answer is yes, since the evil and the remedies are known.

Restrictions must be imposed to limit indiscriminate burning and land clearing, and to prevent all unnecessary destruction. In some cases, new agricultural methods must be brought into use; in others, cultivation of any kind must be prohibited. At times, migration of populations from areas that are too arid and too poor towards richer centers should be helped and encouraged. The work of the native population must be made more productive. New resources should be made available to them through the development of crops suitable to the environment. Sometimes reforestation would have to be carried out and often forest protection would be indicated.

In this field, considerable research and many experiments have already been undertaken by various countries, but there is, of course, a wide gap between theory and practice. In our opinion, the salvation of Africa is a gigantic task, requiring great tenacity for several generations, which can be achieved only if undertaken on an international scale. Without a common program, adapted to the requirements of individual countries but carried out simultaneously wherever possible, the governments responsible for Africa will always hesitate to act. Left to their own devices, they will prefer to defer expenditures and the adoption of regulations, and will refuse to advise on 
actions to be taken if their suggestions are not carried out at the same time by their neighbors, who for some reason might find such an effort too troublesome a burden.

We also believe that however intelligent, praiseworthy, and timely any particular measure may be, if it is applied within geographical limits that are too narrow, it will fail to achieve worthwhile results simply because these would not be commensurate with the scale of the African continent. All African countries are concerned. Forest masses yield an influence over wide distances and what is done in one country may have repercussions in other distant countries. Pooling of effort, joint research, and the synchronizing of undertakings appear to us imperative if failure is to be avoided.
As a beginning, we believe that, within the framework of the international agencies, an office for the protection of African soils and forests could first usefully be entrusted with the study of all these problems; later this office would become well-qualified to promote policies of protection that should be adhered to by all governments. It would also become the agency empowered to make recommendations and suggest measures that should be adopted, and to keep under observation the evolution of a continent that at present seems doomed to become unproductive grassland or even a desert.

Reprinted from Unasylva 1(1): 5-11 (1947), with minor revisions. Photographs courtesy of Ministére de la France d'Outre-Mer. 